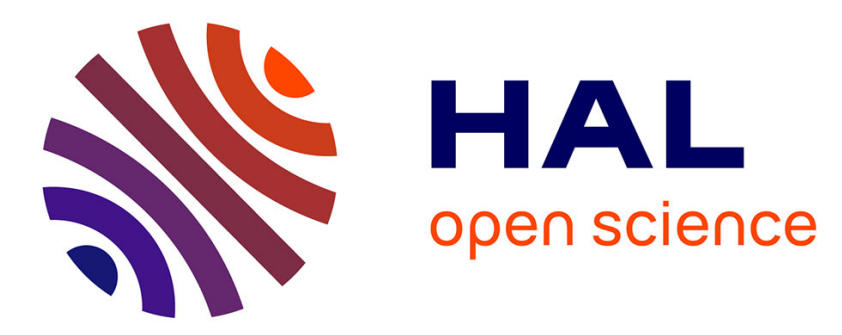

\title{
Medial temporal lobe epilepsy associated with hippocampal sclerosis is a distinctive syndrome
}

Young Joo No, Chiara Zavanone, Franck Bielle, Vi-Huong Nguyen-Michel, Yves Samson, Claude Adam, Vincent Navarro, Sophie Dupont

\section{- To cite this version:}

Young Joo No, Chiara Zavanone, Franck Bielle, Vi-Huong Nguyen-Michel, Yves Samson, et al.. Medial temporal lobe epilepsy associated with hippocampal sclerosis is a distinctive syndrome. Journal of Neurology, 2017, pp.1-7. 10.1007/s00415-017-8441-z . hal-01494497

\section{HAL Id: hal-01494497 https://hal.sorbonne-universite.fr/hal-01494497}

Submitted on 23 Mar 2017

HAL is a multi-disciplinary open access archive for the deposit and dissemination of scientific research documents, whether they are published or not. The documents may come from teaching and research institutions in France or abroad, or from public or private research centers.
L'archive ouverte pluridisciplinaire HAL, est destinée au dépôt et à la diffusion de documents scientifiques de niveau recherche, publiés ou non, émanant des établissements d'enseignement et de recherche français ou étrangers, des laboratoires publics ou privés. 


\section{Medial temporal lobe epilepsy associated with hippocampal sclerosis is a distinctive syndrome}

Young Joo $\mathrm{No}^{1}$, Chiara Zavanone ${ }^{1}$, Franck Bielle ${ }^{2,5,6}$, Vi-Huong Nguyen-Michel ${ }^{3}$, Yves Samson ${ }^{4,5,6}$ Claude $^{2}$ Adam $^{5}, 7$, Vincent Navarro ${ }^{3,5,6,7}$, Sophie Dupont ${ }^{1,5,6,7}$

${ }^{1}$ AP-HP, GH Pitie-Salpêtrière-Charles Foix, Rehabilitation Unit, F-75013, Paris, France.

${ }^{2}$ AP-HP, GH Pitie-Salpêtrière-Charles Foix, Department of neuropathology, F-75013, Paris, France.

${ }^{3}$ AP-HP, GH Pitie-Salpêtrière-Charles Foix, Department of Clinical Neurophysiology, F-75013, Paris, France

${ }^{4}$ AP-HP, GH Pitie-Salpêtrière-Charles Foix, Stroke Unit, Hôpital de la Pitié-Salpêtrière, F-75013, Paris, France

${ }^{5}$ Brain and Spine Institute (ICM ; INSERM UMRS1127, CNRS UMR7225, UPMC) F-75013, Paris, France.

${ }^{6}$ Sorbonne University, UPMC Univ. Paris 06, F-75005, Paris, France.

${ }^{7}$ AP-HP, GH Pitie-Salpêtrière-Charles Foix, Epileptology Unit, F-75013, Paris, France

\section{Address correspondence to:}

Pr S Dupont, Epileptology Unit and Rehabilitation Unit

Hôpital de la Salpêtrière

47, boulevard de l'Hôpital

75651 Paris cedex 13, France

Phone: (33) 142164115

FAX: (33) 142160303

E-mail : sophie.dupont@aphp.fr 


\begin{abstract}
Epileptic syndromes are distinctive disorders with specific features which, when taken together, permit a specific diagnosis. There is actually a debate on that medial temporal lobe epilepsy with hippocampal sclerosis is an epileptic syndrome. To address this issue, we searched for discriminative semiological features between temporal lobe epilepsy patients with hippocampal sclerosis (TLE-HS patients or group 1), TLE patients with medial structural lesion other than hippocampal sclerosis or in MRI-negative cases with medial onset on further investigations (group 2) and lateral TLE patients (LTLE or group 3). We retrospectively collected data from medical and EEG-video records of 523 TLE patients, referred for surgery to the Pitié-Salpêtrière Epileptology Unit between 1991 and 2014. We identified 389 patients belonging to group 1, 61 patients belonging to group 2, and 73 patients belonging to group 3 and performed a comparative analysis of their clinical data and surgical outcomes. TLE-HS patients (group 1): (i) began epilepsy earlier (11 \pm 9 vs. $20 \pm 10$ vs. $15 \pm 9$ years); (ii) exhibited more frequently early febrile convulsions (FC) (59\% vs 7\% vs 5\%); (iii) presented more: ictal gestural automatisms ( $90 \%$ vs $54 \%$ vs $67 \%$ ), dystonic posturing ( $47 \%$ vs $20 \%$ vs $23 \%$ ), and secondary generalized tonicclonic seizures (GTCS) (70\% vs 44\% vs 48\%) as compared to both groups 2 and 3 patients (all p <0.001). With respect to auras, abdominal-visceral auras were more reported by TLE-HS than by LTLE patients (49\% vs $16 \%)$. Three cardinal criteria correctly classified $94 \%$ of patients into TLE-HS group: history of FC, dystonic posturing, and secondary GTCS. Postoperative outcome was significantly better in TLE-HS group than in the two other groups ( $\mathrm{p}=0.03$ and 0.003 ). Our study demonstrates that cardinal criteria are reliably helpful to distinguish patients with TLE-HS from those with other TLE and may allow considering TLE-HS as a distinctive syndrome.
\end{abstract}

$\underline{\text { Key words: }}$ medial temporal lobe epilepsy, hippocampal sclerosis, lateral lobe epilepsy, syndrome. 
Dupont et al.3

\section{Introduction}

In its new classification, the International League Against Epilepsy (ILAE) Commission on Classification and Terminology has defined an electroclinical syndrome as a complex of clinical features, signs, and symptoms that together define a distinctive, recognizable clinical disorder [1]. Syndromes are distinctive disorders identifiable on the basis of a typical age onset, specific electroclinical characteristics, and often other features which, when taken together, permit a specific diagnosis. The diagnosis in turn often has implications for treatment, management, and prognosis. The term constellation refers to those entities that can not be classified as syndromes with a reliable agreement. With this new approach, medial temporal lobe epilepsy with hippocampal sclerosis (HS) has been classified as a distinctive constellation but not as a syndrome. A consensus group that specifically focused on this question in 2004 was in favour of considering medial temporal lobe epilepsy with HS to be a subtype of a greater syndrome of medial temporal lobe epilepsy regardless of the cause [2]. The question, as whether medial temporal lobe epilepsy with HS should be considered a subtype of a broader syndrome of temporal lobe epilepsy (TLE) or a syndrome on its own remains open. To gain further insight into this issue, our study intended to compare a large population of well-defined TLE patients with HS to TLE patients with medial structural lesion other than hippocampal sclerosis or in MRI-negative cases with medial onset on further investigations and to patients suffering from lateral neocortical temporal lobe epilepsy (LTLE). We asked here whether a history of early events, the age of onset, subjective and objective ictal features could represent specific features of TLE-HS or not, and might provide a useful additional diagnostic framework to consider TLE-HS as a distinctive syndrome. 


\section{Material and methods}

\section{Patients}

Patients included were followed in the Epilepsy Unit of the Pitié-Salpêtrière Hospital in Paris. They all had suffered from refractory temporal lobe epilepsy (TLE) and undergone video-EEG examinations between 1991 and 2014.

Criteria for inclusion were: 1) a well defined refractory TLE with at least one video-EEG record of a seizure, 2) a structural MRI (preliminary examinations were performed on a 1.5 T MRI up to 2007 and then on a 3T MRI; FLAIR sequences were implemented in 1996).

All patients gave their informed written consent at the time of the video-EEG exam for further publication of data related to their epilepsy.

Patients with dual pathology on MRI were excluded from the study.

Data concerning patients with refractory TLE associated with hippocampal sclerosis have ever been published elsewhere $[3,4]$.

\section{Collection of data}

We retrospectively reviewed all medical records and all charts of the seizures of 551 patients who fulfilled these criteria, to gather the following data: i) demographic and anamnestic data related to epilepsy (sex, age, age at seizure onset, early events such as febrile convulsions, or head trauma), ii) aetiological data: (existence and type of lesion on structural MRI), iii) subjective seizure features (i.e. aura characteristics): report and description of each aura and category of auras (an aura was considered as present if associated with at least one, but not necessarily all, of the patient's seizures, auras presumed to originate in similar brain regions were grouped together resulting in eleven distinct categories of aura), iv) objective seizure features that were considered present if associated with at least one, not necessarily all, of the patient's seizures and consisted in: objective non motor ictal signs including gestural automatisms (including walking around), oroalimentary automatisms (chewing-swallowing-smacking-licking), mimetic automatisms (expressing a positive or negative affect such as grimacing-smiling-laughing-crying) and language disorders (verbal automatisms, vocalization, ictal speech, dysphasia); objective motor ictal signs including dystonic posturing of the upper and lower limbs, clonus, version defined as head/eye deviation at any time during a partial seizure except just before the secondary tonicclonic phase and presence of secondarily generalized tonic clonic seizures (GTCS) and v) surgery outcome: if surgery took place the postoperative outcome was defined with a simplified Engel's classification (Engel's class I: seizure free patients and those who experienced only simple partial seizures, or drug withdrawal seizures, 
Engel's class II-III-IV patients: those in whom complex seizures were not abolished and surgery outcome was judged as truly unsatisfactory), postoperative outcome was assessed at least one year after surgery.

\section{Classification of patients}

Based on the presurgical findings including EEG-video recordings and structural MRI in all cases and sometimes on additional exams (FDG-PET, ictal SPECT and SEEG), we separated the whole TLE group into three groups:

- Group 1 or TLE-HS group: patients with refractory TLE and with MRI features suggestive of hippocampal sclerosis

- Group 2 : TLE patients with medial structural lesion other than hippocampal sclerosis or in MRI-negative cases with medial onset on further investigations

- Group 3 or LTLE group: patients with a focus located within the lateral temporal lobe structures For groups 2 and 3 patients, localization of the onset zone was either established on the concordance of electroclinical data and the localization of the lesion, or in the absence of lesion on nuclear imaging $(n=33)$, and/or SEEG $(n=24)$.

\section{Statistical analysis}

Statistical analysis was performed by using MedCalc software.

The distribution of each clinical variable was compared between group 1, 2 and 3 using Fisher's exact test (twotailed). For all tests, to counteract the problem of multiple comparisons, we applied a Bonferroni correction: only $p$ values $\leq 0.001$ were considered statistically significant.

In a second step, the seizure free outcome in the three groups was compared using Fisher's exact test (twotailed). For this analysis, two-tailed error probabilities smaller than $p<0.05$ were considered to be significant. Age at onset was compared in the three groups using an ANOVA analysis. The significance level was defined as $p<0.05$.

In a third step, we performed a stepwise discriminant analysis to determine whether the combination of the statistical significant variables that we had previously identified could help us to reliably distinguish patients belonging to the three groups and which combination was the most reliable. 


\section{Results}

\section{Global population description}

551 TLE patients were initially selected. 410 patients underwent surgery. Postoperative outcome could be reliably determined in 384 patients.

The inability to reliably determine the exact localization of the epileptic focus within the temporal lobe led us to exclude 13 patients. Fifteen other patients were excluded because of incomplete data on seizures.

On the remaining 523 patients, patients were classified as following:

- 389 patients belonged to the TLE-HS group 1: 213 women and 176 men, 47\% experienced right MTLE and 53\% left MTLE. 79\% of patients had a history of early events, mainly febrile convulsions (59\%). The median age at onset was $11 \pm 9$ years. $83 \%$ underwent surgery and $86 \%$ belonged to Engel's class I. $62 \%$ of patients had confirmed HS diagnosis on surgical pathology. Most of the older pathological reports could not been retrieved. 61 belonged to the group 2: 32 women and 29 men, 56\% suffered from right MTLE and 44\% from left MTLE. Only 28\% of patients had a history of early events, mainly head trauma (15\%). The median age at onset was $20 \pm 10$ years. $18 \%$ of these patients had no lesion on MRI, $33 \%$ a dysembryoplastic neuroepithelial tumour (DNET), 18\% a dysplasia, $7 \%$ a cavernoma, and $24 \%$ various lesions (ganglioma, cystic lesions, gliosis...). $64 \%$ underwent surgery and 72\% belonged to Engel's class I.

Histopathological examination was missing in one patient, and revealed for the other patients: a dysembryoplastic neuroepithelial tumour in 16 , no specific lesion in 12 , a cavernoma in 3 , a dysplasia in 3 , an unclassified low grade tumour in 2, a ganglioglioma in 2 , a dual pathology in one and an epidermoïd cyst in one

- 73 belonged to the group 3: 40 women and 33 men, 49\% suffered from right TLE and 51\% from left TLE. Only $27 \%$ of patients had a history of early events, mainly head trauma (12\%). The median age at onset was $15 \pm 9$ years. Lesions on MRI were classified as following: no lesion: $30 \%$; DNET: $18 \%$, cortical dysplasia: $19 \%$ and various lesions including ganglioma, cystic lesions, gliosis...: 25\%. $62 \%$ underwent surgery and $62 \%$ belonged to Engel's class I. Histopathological examination was missing in four patients, and revealed for the other patients: the absence of specific lesion in 15, a dysembryoplastic neuroepithelial tumour in 7, a ganglioglioma in 6, a cavernoma in 4, a dysplasia in 2 , a glial scar in 2, an unclassified low grade tumour in 2, an epidermoïd cyst in one, an arteriovenous 
malformation in one, an angiocentric glioma in one, an unclassified cyst in one, a pleomorphic xanthoastrocytoma grade II in one and an unclassified grade I glioneuronal tumour in one.

Distribution and type of auras and objective signs in the three groups are depicted in the table 1.

TLE-HS group versus TLE patients with medial structural lesion other than hippocampal sclerosis or in MRI-negative cases with medial onset on further investigations (table 1)

TLE-HS group differed significantly in terms of:

- $\quad$ Age at onset $(p<0.001)$

- $\quad$ History of febrile convulsions $(p<0,000000001)$

- Presence of gestural automatisms ( $p<0,000000001)$, oroalimentary automatisms $(p=0.001)$, vocalization $(p=0.001)$, dystonic posturing $(p=0.00004)$ and version $(p=0.00069)$ during seizure

- Existence of secondary generalized tonic clonic seizures $(p=0.0001)$

- $\quad$ Postoperative outcome $(\mathrm{p}=0.03)$

Globally, the frequency and distribution of auras could not help to statistically significantly distinguish between TLE-HS patients and TLE patients with medial structural lesion other than hippocampal sclerosis or in MRInegative cases with medial onset on further investigations. .

\section{TLE-HS group versus LTLE group (table 1)}

TLE-HS group differed significantly of LTLE group in terms of:

- $\quad$ Age at onset $(p<0.001)$

- $\quad$ History of febrile convulsions $(p<0,000000001)$

- $\quad$ Presence of an abdomino-visceral aura $(p=0.000018)$

- Presence of gestural automatisms $(p=0.000001)$, dysphasia $(p=0.0000096)$, dystonic posturing $(p=0.00016)$ during seizure

- Existence of secondary generalized tonic clonic seizures $(p=0.0002)$

- Postoperative outcome $(\mathrm{p}=0.003)$

TLE patients with medial structural lesion other than hippocampal sclerosis or in MRI-negative cases with medial onset on further investigations versus LTLE group (table 1) 
TLE patients with medial structural lesion other than hippocampal sclerosis or in MRI-negative cases with medial onset on further investigations did not differ significantly of LTLE group except for the age at onset $(p<0.001)$

\section{Classification of patients}

Three major criteria, i.e., presence of febrile convulsions, presence of dystonic posturing, existence of secondarily GTCS allowed us to correctly classify $94 \%$ of the patients belonging to the TLE-HS group (versus both groups 2 and 3).

Using the same criteria, only respectively, $40 \%$ and $38 \%$ of the patients belonging to groups 2 and 3 were correctly classified.

Adding all statistically significant clinical variables improved the correct classification of patients belonging to TLE-HS group to $96 \%$. 


\section{Discussion}

This study of a very large population of refractory TLE patients brings strong arguments to consider TLE-HS as a distinctive syndrome with specific clinical features and a more favourable outcome.

\section{Diagnostic criteria in favour of TLE-HS}

In this study, we demonstrated that cardinal criteria may reliably help to distinguish between TLE-HS patients, TLE patients with medial structural lesion other than hippocampal sclerosis or in MRI-negative cases with medial onset on further investigations and LTLE patients: history of febrile convulsions, age at onset, presence of gestural automatisms and dystonic posturing during seizure and existence of secondarily GTCS. Furthermore, we demonstrated that a diagnosis of TLE-HS can be made with a high degree of confidence in the presence of only three major criteria: presence of febrile convulsions, dystonic posturing, and secondarily GTCS.

\section{Relevant diagnostic criteria}

Nearly $60 \%$ of our patients in the TLE-HS group reported to have febrile convulsions as an early event related to epilepsy, whereas only $7 \%$ and $5 \%$ were reported in TLE patients with medial structural lesion other than hippocampal sclerosis or in MRI-negative cases with medial onset on further investigations and LTLE groups, respectively. O'Brien et al [5]. reported a similar observation but to a smaller degree by comparing TLE-HS with neocortical temporal epilepsy with lesion. Similar association was reported by several other authors [6-8]. Our study also showed that age at epilepsy onset was significantly lower in patients with TLE-HS than in TLE with medial structural lesion other than hippocampal sclerosis or in MRI-negative cases with medial onset on further investigations (10 years older) and LTLE (4 years older). In a series of 67 patients with MTLE, French et al. [8] reported that seizures began at or before 16 years of age in $88 \%$ of patients, the mean age at seizure onset being 9 years. In accordance to our findings, Foldvary et al. [9] reported a mean age at seizure onset of 8.4 years in patients with MTLE and 18.5 years in a group of patients with neocortical temporal lobe epilepsy. Mixed together, these two criteria (febrile convulsions and younger age at onset) certainly reflect a specific natural history and pathophysiopathology of TLE-HS. It could be linked in turn to genetic determinants.

Presence of gestural automatisms and dystonic posturing during seizure were also significantly associated to TLE-HS group. Similar associations with MTLE were described by previous reports with regard to the localization (medial or neocortical) [10-12]. O'Brien [5] reported that dystonic posturing occurred more frequently in seizures of TLE-HS patients. Our team [11] has already shown that the association of dystonic posturing and gestural automatism was a reliable sign to distinguish TLE-HS from LTLE. Mihara et al. [12] and Foldvary et al [9] also found dystonic posturing and automatisms more common in MTLE. Additionally we 
observed a higher incidence of secondary generalized tonic-clonic seizures (GTCS) in TLE-HS compared to the other two groups. This finding was rather unexpected since secondarily GTCS are usually considered as rare in TLE-HS [2] with the explanation that antiepileptic drugs better control secondarily generalization than focal seizures. Yet, other studies have ever found similar results. For example, Bone et al. [13] found a positive association between the presence of HS and regular occurrence of secondarily GTCS in 171 patients with TLE.

\section{Non relevant diagnostic criteria}

Aura features could not help to distinguish reliably between TLE-HS and TLE patients with medial structural lesion other than hippocampal sclerosis or in MRI-negative cases with medial onset on further investigations. More unexpectively, there was only one type of auras (abdomino-visceral sensation) that differentiates TLE patients with medial structural lesion other than a hippocampal sclerosis or in MRI-negative cases with medial onset on further investigations from LTLE groups. This result is however clinically interesting. The other numerous types of auras occurred more rarely and were not distinctive. This recalls the high variability of auras and of their associations in TLE-HS [3]. We demonstrated in a recent work that the varieties of auras and associations of auras could not predict surgical outcome in TLE-HS. We have hypothesized that this wide variability of auras and associations of auras experienced by TLE-HS patients was linked to a recruitment of diverse and distributed brain regions. TLE patients with medial structural lesion other than a hippocampal sclerosis or in MRI-negative cases with medial onset on further investigations and LTLE patients had the same variability of auras, but with significantly less abdomino-visceral semiology in LTLE group. By contrast, this suggests a strong link between HS and the abdomino-visceral network, mainly located in the insula [14,15].

\section{TLE-HS: a distinct network syndrome?}

So we have different types of arguments in favour of a distinct TLE-HS entity: i) the natural history of the disease beginning earlier and after febrile convulsions, ii) the abdomino-visceral component that prevails in the subjective semiology, iii) the objective pattern combining gestural and oroalimentary automatisms and more frequent secondarily generalized tonic clonic seizures and finally iv) the better postoperative outcome. These features tell us that TLE-HS involves wide areas beyond the sclerotic hippocampus in a specific manner that is missing in the other TLE types. This suggests a specific network of propagations and a large-scale functional network as recent functional imaging studies, especially connectivity studies, have revealed it $[16,17]$. Recently, Coan et al.[18] found distinct patterns of hemodynamic responses during the apparently same 
interictal epileptiform discharges patterns recorded by electroencephalography-correlated functional MRI (EEGfMRI) in MTLE patients with hippocampal sclerosis or without any MTL lesion. They pointed the enhancement of the ipsilateral insula in the TLE-HS group as compared to theTLE patients with medial structural lesion other than hippocampal sclerosis or in MRI-negative cases with medial onset on further investigations. Concerning postoperative outcome, a recent study [19] has also suggested that specific networks connectivity alterations could predict failure to surgery in MTLE. It was found that the existence of bihemispheric alterations of thalamotemporal structural networks was a predictor of bad postoperative outcome. Finally, a better post-operative outcome in our TLE-HS patients may indicate a more intra-group consistency than in other compared groups.

\section{Limitation of the study}

Our analyses were retrospective, based on medical and seizure charts and we acknowledge the limitations of a retrospective study. In addition, the accuracy of the classification provided by the stepwise discriminant analysis will need in the future to be validated in independent cohorts.

\section{Conclusion}

Our study brings further arguments in comparison with TLE with medial structural lesion other than hippocampal sclerosis or in MRI-negative cases with medial onset on further investigations and LTLE to consider TLE-HS as a distinct syndrome with a sufficient cluster of signs and symptoms to make up a syndromic diagnostic entity.

Conflicts of interest: The authors have nothing to declare 


\section{References}

1. Berg AT, Berkovic SF, Brodie MJ, et al. (2010)Revised terminology and concepts for organization of seizures and epilepsies: Report of the ILAE Commission on Classification and Terminology, 20052009 Epilepsia 51(4):676-685

2. Wieser HG, ILAE Commission on Neurosurgery of Epilepsy. ILAE Commission Report. (2004) Mesial temporal lobe epilepsy with hippocampal sclerosis. Epilepsia 45:695-714

3. Dupont S, Samson Y, Nguyen-Michel VH, et al. (2015) Are auras a reliable clinical indicator in medial temporal lobe epilepsy with hippocampal sclerosis? European Journal of Neurology 22: 1310-1316

4. Dupont S, Samson Y, Nguyen-Michel VH, et al. (2015) Lateralizing value of semiology in medial temporal lobe epilepsy Acta Neurol Scand 132(6):401-409

5. O'Brien TJ, Kilpatrick C, Murrie V, et al. (1996) Temporal lobe epilepsy caused by mesial temporal sclerosis and temporal neocortical lesions. A clinical and electroencephalographic study of 46 pathologically proven cases. Brain 119, 2133-2141

6. Saygi S, Spencer SS, Scheyer R, et al. (1994) Differentiation of Temporal Lobe Ictal Behavior Associated with Hippocampal Sclerosis and Tumors of Temporal Lobe. Epilepsia 35(4):737-742

7. Burgerman RS, Sperling MR, French JA, Saykin AJ, O'Connor MJ. (1995) Comparison of mesial versus neocortical onset temporal lobe seizures: neurodiagnostic findings and surgical outcome. Epilepsia 36(7):662-670

8. French JA, Williamson PD, Thadani VM, et al. (1993) Characteristics of medial temporal lobe epilepsy: I. Results of history and physical examination. Ann Neurol. 34(6):774-780

9. Pfänder M, Arnold S, Henkel A, et al. (2002) Clinical features and EEG findings differentiating mesial from neocortical temporal lobe epilepsy. Epileptic Disord. 4(3):189-195

10. Foldvary N, Lee N, Thwaites G, et al. (1997) Clinical and electrographic manifestations of lesional neocortical temporal lobe epilepsy. Neurology 49:757-763.

11. Dupont S, Semah F, Boon P, et al. (1999) Association of ipsilateral automatisms and contralateral dystonic posturing: a clinical feature differentiating medial from neocortical temporal lobe epilepsy Archives of Neurology 56(8) :927-932

12. Mihara T, Inoue Y, Hiyoshi T, et al. (1993) Localizing value of seizure manifestations of temporal lobe epilepsies and the consequence of analyzing their sequential appearance. Jpn J Psychiatry Neurol. 47(2):175-182

13. Bone B, Fogarasi A, Schulz S, et al. (2012) Secondarily generalized seizures in temporal lobe epilepsy. Epilepsia 53(5):817-824

14. Penfield W, Jasper H. Epilepsy and the functional anatomy of the human brain. 1st ed. Boston: Little Brown; 1954

15. Tufenkjian K, Lüders HO. (2012) Seizure semiology: its value and limitations in localizing the epileptogenic zone. J Clin Neurol 8:243-250

16. Jin SH, Jeong W, Chung CK (2015) Mesial temporal lobe epilepsy with hippocampal sclerosis is a network disorder with altered cortical hubs Epilepsia 56(5):772-779 
17. Besson P, Dinkelacker V, Valabregue R, et al. (2014) Structural connectivity differences in left and right temporal lobe epilepsy Neuroimage 100:135-44

18. Coan AC, Campos BM, Beltramini GC, Yasuda CL, Covolan RJM, Cendes F (2014) Distinct functional and structural MRI abnormalities in mesial temporal lobe epilepsy with and without hippocampal sclerosis Epilepsia, 55(8):1187-1196

19. Keller SS, Richardson MP, Schoene-Bake JC, et al. (2015) Thalamotemporal Alteration and Postoperative Seizures in Temporal Lobe Epilepsy Ann Neurol 77:760-774 
Dupont et al.14

Table Titles

Table 1 Statistical comparison of each clinical variable between all groups of patients 


\begin{tabular}{|c|c|c|c|}
\hline & $\begin{array}{c}\text { group } 1(\mathrm{n}=389) \\
\text { Vs } \\
\text { group } 2(\mathrm{n}=61)\end{array}$ & $\begin{array}{c}\text { group } 1(\mathrm{n}=389) \\
\text { Vs } \\
\text { group } 3(\mathrm{n}=73)\end{array}$ & $\begin{array}{c}\text { group } 2(\mathrm{n}=61) \\
\text { Vs } \\
\text { group } 3(\mathrm{n}=73)\end{array}$ \\
\hline FC & $59 \%$ vs $7 \%, *$ & $59 \%$ vs 5\%, * & $7 \%$ vs $5 \%, N S$ \\
\hline Age at onset (years) & $11 \pm 9$ vs $20 \pm 10, *$ & $11 \pm 9$ vs $15 \pm 9, *$ & $20 \pm 10$ vs. $15 \pm 9, *$ \\
\hline Presence of aura & $11 \%$ vs $9 \%, N S$ & $\begin{array}{c}11 \% \text { vs } 16 \% \\
N S\end{array}$ & $9 \%$ vs $16 \%, N S$ \\
\hline \multicolumn{4}{|l|}{ Type of aura } \\
\hline autonomic & $50 \%$ vs $33 \%, N S$ & $\begin{array}{c}50 \% \text { vs } 22 \% \\
N S\end{array}$ & $33 \%$ vs $22 \%, N S$ \\
\hline abdominal-visceral & $49 \%$ vs $20 \%, N S$ & $49 \%$ vs $16 \%$, * & $20 \%$ vs $16 \%, N S$ \\
\hline psychoaffective & $32 \%$ vs $26 \%, N S$ & $\begin{array}{c}32 \% \text { vs } 14 \% \\
N S\end{array}$ & $26 \%$ vs $14 \%, N S$ \\
\hline experiential & $21 \%$ Vs $25 \%, N S$ & $\begin{array}{c}21 \% \text { vs } 15 \%, \\
N S\end{array}$ & $25 \%$ vs $15 \%, N S$ \\
\hline non specific & $14 \%$ vs $21 \%, N S$ & $\begin{array}{c}14 \% \text { vs } 16 \% \\
\text { NS }\end{array}$ & $21 \%$ vs $16 \%, N S$ \\
\hline somatosensory & $11 \%$ vs $8 \%, N S$ & $11 \%$ vs $7 \%, N S$ & $8 \%$ vs $7 \%, N S$ \\
\hline visual & $10 \%$ vs $15 \%, N S$ & $\begin{array}{c}10 \% \text { vs } 14 \% \\
\text { NS }\end{array}$ & $15 \%$ vs $14 \%, N S$ \\
\hline auditory & $7 \%$ vs $9 \%, N S$ & $7 \%$ vs $10 \%, N S$ & $9 \%$ vs $10 \%, N S$ \\
\hline gustatory & $7 \%$ vs $7 \%, N S$ & $7 \%$ vs $4 \%, N S$ & $7 \%$ vs $4 \%, N S$ \\
\hline vestibular & $5 \%$ vs $7 \%, N S$ & $5 \%$ vs $8 \%, N S$ & $7 \%$ vs $8 \%, N S$ \\
\hline olfactory & $3 \%$ vs $7 \%, N S$ & $3 \%$ vs $1 \%, N S$ & $7 \%$ vs $1 \%, N S$ \\
\hline \multicolumn{4}{|l|}{$\begin{array}{l}\text { Non motor objective } \\
\text { signs }\end{array}$} \\
\hline gestural automatisms & $90 \%$ vs $54 \%$, * & $90 \%$ vs $67 \%, *$ & $54 \%$ vs $67 \%, N S$ \\
\hline $\begin{array}{l}\text { oroalimentary } \\
\text { automatisms }\end{array}$ & $78 \%$ vs $64 \%$, * & $\begin{array}{c}78 \% \text { vs } 70 \% \\
N S\end{array}$ & $64 \%$ vs $70 \%, N S$ \\
\hline verbal automatisms & 41 vs $21 \%, N S$ & $\begin{array}{c}41 \% \text { vs } 42 \%, \\
N S\end{array}$ & $21 \%$ vs $42 \%, N S$ \\
\hline vocalization & $26 \%$ vs $8 \%$, * & $\begin{array}{c}26 \% \text { vs } 14 \%, \\
N S\end{array}$ & $8 \%$ vs $14 \%, N S$ \\
\hline ictal speech & $12 \%$ vs $11 \%, N S$ & $\begin{array}{c}12 \% \text { vs } 16 \%, \\
N S\end{array}$ & $11 \%$ vs $16 \%, N S$ \\
\hline dysphasia & $2 \%$ vs $7 \%, N S$ & $2 \%$ vs $15 \%, *$ & $7 \%$ vs $15 \%, N S$ \\
\hline mimetic automatisms & $6 \%$ vs $5 \%, N S$ & $6 \%$ vs $15 \%, N S$ & $5 \%$ vs $15 \%, N S$ \\
\hline \multicolumn{4}{|l|}{ Motor objective signs } \\
\hline dystonic posturing & $47 \%$ vs $20 \%$, * & $47 \%$ vs $23 \%$, * & $20 \%$ vs $23 \%, N S$ \\
\hline clonus & $17 \%$ vs $10 \%, N S$ & $\begin{array}{c}17 \% \text { vs } 15 \% \\
N S\end{array}$ & $10 \%$ vs $15 \%, N S$ \\
\hline version & $44 \%$ vs $21 \%$, * & $\begin{array}{c}44 \% \text { vs } 26 \% \\
N S\end{array}$ & $21 \%$ vs $26 \%, N S$ \\
\hline Secondarily GTCS & $70 \%$ vs $44 \%$, * & $70 \%$ vs $48 \%$, * & $44 \%$ vs $48 \%, N S$ \\
\hline $\begin{array}{l}\text { Postoperative outcome } \\
\text { (Engel's class I) }\end{array}$ & $\begin{array}{c}86 \% \text { vs } 72 \% \\
(p=0.03)\end{array}$ & $\begin{array}{c}86 \% \text { vs } 62 \% \\
(p=0.003)\end{array}$ & $72 \%$ vs $62 \%$ \\
\hline
\end{tabular}

Table 1 Statistical comparison of each clinical variable between all groups of patients

$*=$ Statistically significant according to Bonferroni correction $=p \leq 0.001$ 
$\mathrm{NS}=$ non significant

Group 1 or TLE-HS group: patients with refractory TLE and with MRI features suggestive of hippocampal sclerosis

Group 2 : TLE patients with medial structural lesion other than a hippocampal sclerosis or in MRI-negative cases with mesial onset on further investigations

Group 3 or LTLE group: patients with a focus located within the lateral temporal lobe structures 